\title{
Effects of the Life Curriculum Integrating the Happiness Teaching and the Mind Mapping Teaching Methods on the Imagination for Second Graders
}

\author{
Yue-Shi Yang, Chun-Yi Lee, Tsai-Feng Cheng, and Shi-Jer Lou
}

\begin{abstract}
This study aimed to assess the effects of the life curriculum integrating the happiness and the mind mapping teaching methods on second graders' imagination. A single set of experimental method was implemented in a class of 23 second graders for 2 hours a week, and lasting for 12 weeks in total. The life curriculum integrates different teaching methods, including the traditional teaching, the happiness teaching, the mind mapping teaching, and the happiness and mind mapping integration. Changes in imagination by observing the creative works done by the students were assessed. Qualitative analysis and students' responses and feedbacks in class were analyzed. After conducting five tests on the changes in the students' imagination, One-Way ANOVA was implemented to analyze the collected data. Through the integrating happiness and the mind mapping teaching into life curriculum, the findings of the study reveal that the imagination and creativity in the works of the students are greatly observed; the students' imagination has obviously improved; and the students have highly accepted this curriculum. Additionally, the happiness and mind mapping teaching method for imagination cultivation has been developed in this study.
\end{abstract}

Index Terms - Happiness, imagination, life curriculum, mind mapping.

\section{INTRODUCTION}

Albert Einstein said, "Imagination is more important than knowledge. For knowledge is limited to all we now know and understand, while imagination embraces the entire world, and all there ever will be to know and understand." Imagination can lead us to some field which we have not yet discovered. Research indicates that students from suburban areas are with less ability in analogical reasoning than those from urban areas [1]. They also lack technological creativity more than those from those in urban areas [2]. They often imitate works by their teachers or classmates without creative thinking. Therefore, the researchers try to teach with a different method to stimulate their imagination. The researchers intend to know if mind mapping teaching can improve students' imagination. Teachers are expected to adopt creative way of teaching and diverse ways of evaluation on learners in order to increase their learning efficiency and to explore the infinity of their ability. This methodology helps learners systematically reorganize the latest and old knowledge with both graphs and word description and then build connections in order to absorb, digest, and easily memorize it. This keeps

Manuscript received December 1, 2016; revised April 17, 2017.

Yue-Shi Yang, Chun-Yi, and Shi-Jer Lou are with the National Pingtung University of Science and Technology, Taiwan (e-mail: smileporpoise@yahoo.com.tw, cyl@npust.edu.tw, lou@npust.edu.tw).

Tsai-Feng Cheng is with the National Kaohsiung Normal University, Taiwan (e-mail: t2151@nknu.edu.tw). learning highly effective and interesting and strengthens imagination [3]. The purpose of this study aimed to explore effects of happiness teaching on the imagination of the second graders, what impact can result in when mind mapping teaching is integrated, and the influences that can have when happiness teaching and mind mapping teaching are involved.

\section{LITERATURE REVIEW}

Imagination can be categorized from the aspect of its function, purposes, and procedure. In terms of its function and procedure, [4] imagination is produced through prospection, reproduction, and image creation. In terms of its purposes, [5] described imagination to be either meaningless or meaningful. Additionally, based on the level of creativity, creativity, and originality, imagination can be illusion, reproduction, and image creation. Previous studies described that imagination roots in memory and generates reproductive and innovative imagination.

Mind mapping which is developed by using imagination derive from the experience a person has had. The more experience he has, the more imaginative he is. [6] claimed that creativity can be generated by utilizing mind mapping and modified by creative thinking. [7] notes that illustration in picture books help students with language learning by connecting experiences with new knowledge and help develop logical flow, which shares similar concept in our research. We, furthermore, add in happiness learning and mind mapping in this research to stimulate their imagination shown in their works of art.

Happiness is a positive emotion, [8], a feeling of well-being that a person can have [9]. It is a state of feeling satisfied with life, and feeling greatly positive. [10] stated that happiness derives from the intention of resolving problems when we encounter frustration or challenges. We, therefore, keep practicing changing our thoughts and mind and strengthen our positive thinking to overcome what we are confronting. In this research, we focus on the feelings of being painless, unstrained, satisfied, and excited when students think, say, and act in the daily life. This is what "happiness" refers to in this study. It is going to be observed through a student's conduct, facial expressions, and assignments.

Mind mapping is a learning method put forward by Buzan in the early 1970. To simulate the network operation in our brain, Buzan took a core-concept-centered radiation pattern, called "mind map" [11]. Learning, thinking, creating, and evaluating with the assistance is what we call "mind 
mapping" [12]. [13] indicated that mind mapping engage both left and right brain of learners to learn or to think. They center a main topic and develop related subtopics, which are categorized and layered by colors, drawings, and key words. In summary, mind mapping visualizes thoughts by using tree diagrams. It engages analytic left brain, dominating word and logic, and artistic right brain, dominating colors and drawings. With mind mapping, we center a main topic and develop subtopics that connect with the main topic in a radial diagram.

\section{RESEARCH METHOD}

\section{A. Research Framework}

This study aims to discover the effects of integrating happiness and mind mapping into teaching on learning achievement and imagination development. The teaching plan is structured in the following flow diagram. Subjects in this study were a total of $232^{\text {nd }}$ grade elementary school students.

\section{B. Dependent and Independent Variables}

Independent variables are 1) happiness feelings: to introduce the positive feelings into life courses to make students reveal the feelings in class and show in their work; and 2) mind mapping: to apply the features and skills when making a mind map to teaching to help students learn how to integrate knowledge and thoughts when they do mind mapping. Dependent variables are 1) evaluation on imagination: an evaluation is required to discover differences after a work of a lesson is completed; and 2) imagination assessment: a pre-assessment is given before a course starts. Another assessment will be given at the end of each lesson. For discovering the differences, two versions of assessment sheets will be given alternatively.

\section{Curriculum Design}

In this study, we will adopt "Live our life happily" in a textbook for life curriculum as the theme, including four units Before this experimental teaching starts, we conducted an assessment on students' imagination. After we finished one unit, we graded their works for imagination development which we could observe from their works, and we conducted another assessment afterwards. We also gave them a questionnaire regarding satisfaction with this life curriculum to have comprehensive understanding on whether we meet their demand for learning. In addition, teaching observation was also conducted.

\section{Research Instruments}

\section{1) Creative imagination scale assessment}

The researchers created this scale assessment, based on "Creativity assessment new edition", "Imagination Assessment" and "Imagination Scale". This assessment, including language ability, graphic tests, was applied to assess those two graders for their imagination. eight questions were there in the pre-assessment, and were examined and analyzed the content by three experts. A total of $1502^{\text {nd }}$ graders from two elementary schools in Chiayi County and Pingtung County to participate in our pilot study.

2) Creative imagination scale for student's works
In this study, "Happiness feelings and mind mapping" was introduced into the "Imagination scale evaluation on art works" of life curriculum to observe the changes of imagination and to rate it on the evaluation scale. We first had three experts examine to assure if the content corresponds to the scales the results of these two assessments. For the reliability of the evaluation from the three critics, they were requested to evaluate ten art works from students, and we had a researcher from us and a teacher from arts and humanities field to evaluate these identical art works. Afterwards, three of them went through a discussion to reach an agreement on evaluation standards. The consensus among the three evaluators improves the reliability and the validity of these assessments.

\section{E. Data Analysis}

We adopt quantitative research method to process and analyze the results with the support of qualitative research method to keep observation records. We use the mean, standard deviation, and sorting to analyze and identify the differences in the extent of the imagination revealed in the four art works, and that in the five assessments. We use one-way variance to analyze the results of the four art works and the five assessments on imagination differences. We provide qualitative description to explain the results obtained from the assessments and the evaluation scale, based on the student subjects' feedback on this life curriculum with the integration of the happiness feelings and mind mapping.

\section{RESUlTS AND DisCUSSION}

Table I shows the results of handprint 4 shows a great significant difference in the mean, compared with that of handprint 1, 2, and 3. This demonstrates the highest acceptance and the best learning effectiveness of those students when curriculum courses live were carried out with the integration of happiness feelings and mind mapping. That the result of handprint 3 shows a great significant differences in the mean, compared with that of handprint 2 and 1 , indicates that those students had better acceptance and performance with mind mapping teaching than with happiness feelings teaching and conventional teaching. Comparing the works after happiness teaching with those after conventional teaching, we found differences in results among these art works, but they are subtle. However, we can still observe some progress and improvement in their works and the fact is that happiness feelings involved in teaching boosted their imagination, but it is not significant revealed by the results. We assume that how variety in a work depends on the level of having the sense of happiness an individual has.

TABLE I: RESULTS OF EVALUATION ON HANDPRINT WORKS

\begin{tabular}{lcccc}
\hline Art work & I & II & III & IV \\
\hline Handprint 01 (I) & -- & -- & -- & -- \\
\hline Handprint 02 (II) & 1.83 & -- & -- & -- \\
\hline Handprint 03 (III) & $5.57(*)$ & $3.74(*)$ & -- & \\
\hline Handprint 04 (IV) & $8.22(*)$ & $6.39\left(^{*}\right)$ & $2.65(*)$ & -- \\
\hline${ }^{*} p<0.05$ & & &
\end{tabular}

Table II shows the results of logic in language use shows 
great significant differences in the mean, compared with that of Assessment 1 and 3. This demonstrates that those students had a significant improvement in their language use when we applied mind mapping to live curriculum courses. That the result of Assessment 2 and 1 shows a great significant differences in the mean, compared with that of the pre-assessment, indicates that those students had improved their logic of language use with either mind mapping teaching, or teaching involving happiness feelings teaching. Assessment 4 reveals a significant difference in the mean, compared with Assessment 3, 2, 1 and the pre-assessment. This explains that teaching with the integration of happiness feelings and mind mapping in the courses of live curriculum has a the most significant increase in logic in their language use. In other words, the combination of happiness feelings and mind mapping affect students' learning.

\begin{tabular}{lccccc}
\multicolumn{7}{c}{ TABLE II: RESULTS OF LOGIC IN LANGUAGE USE } \\
\hline Logic & I & II & III & IV & V \\
\hline Pre-assessment (I) & -- & -- & -- & -- & -- \\
\hline Assessment 1 (II) & 0.00 & -- & -- & -- & -- \\
\hline Assessment 2 (III) & $3.48(*)$ & $3.48(*)$ & -- & -- & -- \\
\hline Assessment 3 (IV) & $3.09(*)$ & $3.09\left(^{*}\right)$ & -0.39 & -- & -- \\
\hline Assessment 4 (V) & $6.87(*)$ & $6.87(*)$ & $3.39(*)$ & $3.78(*)$ & -- \\
\hline$p<0.05$ & & & & &
\end{tabular}

TABLE III: RESULTS OF CREATIVITY IN LANGUAGE USE

\begin{tabular}{cccccc}
\hline \multicolumn{6}{c}{ TABLE III: RESULTS OF CREATIVITY IN LANGUAGE USE } \\
\hline $\begin{array}{c}\text { CREATIVITY } \\
\text { PRE-ASSESSMENT } \\
\text { (I) }\end{array}$ & I & II & III & IV & V \\
\hline $\begin{array}{c}\text { ASSESSMENT 1(II) } \\
\text { ASSESSMENT 2 (III) }\end{array}$ & -0.17 & -- & -- & -- & -- \\
\hline $\begin{array}{c}\text { ASSESSMENT 3 } \\
(\text { IV) }\end{array}$ & $2.350(*)$ & $2.70(*)$ & -- & -- & -- \\
\hline $\begin{array}{c}\text { ASSESSMENT 4 (V) } \\
*\end{array}<0.05$ & $6.35(*)$ & $6.52(*)$ & $3.83(*)$ & $4.00(*)$ & -- \\
\hline & & & & & -- \\
\hline
\end{tabular}

Table III shows that those students have had significant improvement in creativity in language use when we applied mind mapping to live curriculum. Compared with Assessment 1 and pre-assessment, Assessment 2 demonstrates a significant difference in the mean. This result tells that those students have had significant improvement in creativity in language use when we applied happiness feelings to live curriculum. These two results display that those students had improved their creativity in language use when we applied either mind mapping teaching, or taught involving happiness feelings. Assessment 4 reveals a significant difference in the mean, compared with Assessment 3, 2, 1 and the pre-assessment. This explains that teaching with the integration of happiness feelings and mind mapping in the courses of live curriculum has the most significant increase in creativity in their language use. In other words, the combination of happiness feelings and mind mapping affect students' learning.

Table IV shows the results that those students have had significant improvement in creativity in graphics use when we applied mind mapping to live curriculum. Compared with Assessment 1 and pre-assessment, a significant difference in the mean is observed in Assessment 2. This result tells that those students have had significant improvement in creativity in graphics use when we applied happiness feelings to live curriculum. These two results display that those students had improved their creativity in graphics use when we applied either mind mapping teaching, or taught involving happiness feelings. Assessment 4 reveals a significant difference in the mean, compared with Assessment 3, 2, 1 and the pre-assessment. This explains that teaching with the integration of happiness feelings and mind mapping in the courses of live curriculum has the most significant increase in creativity in graphics use. In other words, the combination of happiness feelings and mind mapping affect students' learning.

TABLE IV: RESULTS OF CREATIVITY IN GRAPHICS USE

\begin{tabular}{lccccc}
\hline \multicolumn{1}{c}{ Creativity } & I & II & III & IV & V \\
\hline Pre-assessment (I) & -- & -- & -- & -- & -- \\
\hline Assessment 1 (II) & -0.78 & -- & -- & -- & -- \\
\hline Assessment 2 (III) & $2.70(*)$ & $3.48(*)$ & -- & -- & -- \\
\hline Assessment 3 (IV) & $4.00(*)$ & $4.78(*)$ & 1.30 & -- & -- \\
\hline Assessment 4 (V) & $7.74(*)$ & $8.52(*)$ & $5.04(*)$ & $3.74(*)$ & -- \\
\hline${ }^{*} p<0.05$ & & & & &
\end{tabular}

\section{CONCLUSION AND SugGESTIONS}

\section{A. Conclusion}

Teaching with the integration of happiness feelings and mind mapping is good to applied to live curriculum for the 2 nd graders. They had actively participated in classes, had four different topics, and finished art works. During this experimental teaching, the students kept making the imagination go wild. By teaching with the integration of happiness feelings and mind mapping, we could observe significant development of imagination from the art works of those $2^{\text {nd }}$ graders. With this 12 -week teaching experiment, the students have had a great and obvious improvement in the development of imagination observed from their art works. Those works show a more decent logic and creativity. Teaching with the integration of happiness feelings and mind mapping significantly boosts imagination of the $2^{\text {nd }}$ graders. Conventional teaching helps improve the flexibility in language use. When happiness feelings involves in teaching, logic and creativity in language use, logic, flexibility, and creativity of drawing are all improved. When mind mapping involves in teaching, logic, flexibility, and creativity both in language use and of drawing are boosted. This consequence is also applied to the teaching with the integration of happiness feelings and mind mapping. Those Grade 2 students are with high adaption to the life curriculum of this kind with the integration of happiness feelings and mind mapping. those students were active in answering questions and completing art works with great efforts. As we observed from their art works, we found that the total amount of people, who had significantly shown great efforts in making the last handprint, increases to 15 people on the evaluation scale. Meanwhile, works of collages had shown less significant results in terms of efforts devoted into the works. However, the total number of "work very hard" of the last art work in the evaluation scale increases to 11 people.

\section{B. Suggestions}


We encourage instructors to engage happiness feelings into various kinds of subjects or living conditions. This can make learning more relax and students can study and learn more happily. Instructors are also encouraged to adopt mind mapping to develop student's ability in solving problems. When happiness feelings and mind mapping are involved simultaneously, instructors can utilize the condition that provokes happiness feelings and of the language in use to encourage students to properly apply mind mapping to other different subjects or problems to be solved. In this case, the students can develop their ability. From the aspect of research subjects, we suggest that subjects can be from different classes or even from different grades to explore the effect of the curriculum with the integration of happiness feelings and mind mapping on their development of imagination. In terms of research duration, we suggest to extend time to conduct the teaching. Instructors are also encouraged to establish a society related to professional teaching, or one that focus on how to develop imaginative thinking. We also suggest researchers to adopt quasi experimental research and select a controlled class that is with similar condition to an experimental class. Their research can focus on observing and analyzing the results of assessments conducted before and after teaching sessions to discover the impact of this teaching method on the development of student's imagination.

\section{REFERENCES}

[1] C. Y. Liu. (2003). A study of the grade 5 and 6 students' analogical reasoning ability and its influencing factors. Master's thesis, National Pingtung University. [Online]. Available: http://handle.ncl.edu.tw/11296/ndltd/78874958825490878774

[2] Y. I. Li. (2003). The relationships between grade, residence area, birth order, constructive thinking, emotional competence and pupils' technological creativity. Master's thesis, National Sun Yat-sen University, Kaohsiung. [Online]. Available: http://handle.ncl.edu.tw/11296/ndltd/34393908253079142024

[3] Y. X. Sun and Z. B. Chen, Mind Maps Learning Method 2 Reading Master, Taipei, Taiwan, 2005.

[4] H.C. Zhang, Zhang's Dictionary of Psychology, Taipei, Taiwan: Tunghua book, 2007.

[5] P.M. Li, Psychology and the arts, Beijing, China: Capital Normal University, 1996.

[6] X. Y. Cao and X. H. Lin, "The establishment of the scale of imagination," Journal of Research in Education Sciences, vol. 57, no. 4, pp. 1-37, 2012.
[7] Y.R. Lin. (2009). The influence of picture books instruction upon the primary school teacher's creativity teaching and student's creativity performance. Master's thesis, National Taiwan Normal University. [Online].

Availab http://handle.ncl.edu.tw/11296/ndltd/30109000071971064765

[8] J.W. Rao, Emotional Conservation, Taipei, Taiwan: Wunan, 2004.

[9] H. M. Lee and Z. X. Zhu, "The effects of happiness internet intervention program," Journal of STU, vol. 14, no. 1, pp. 275-297, 2012.

[10] C. H. Zheng, "The power of positive thinking," Business Weekly, 974, pp. 57-64, 2006.

[11] K. F. Wang, "Application of mind maps and conceptual module in Chinese reading and writing thinking teaching," Bulletin of Chinese, vol. 43, pp. 263-296, 2008.

[12] Y. X. Sun, Mind Mapping Basics: Multiple Knowledge Management System, Taipei, Taiwan: Yale, 2002.

[13] M. W. Chen, "The effects of incorporating mind mapping with picture-book reading instruction on the reading comprehension ability and creativity of elementary school students," Master's thesis, No. 097TMTC5212002, 2010.

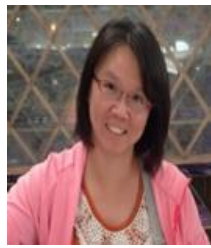

Yue-Shi Yang was born in 1980 in Tainan city. After graduating from the Department of Mathematics and Education in Taitung Teachers College in 2002, she is a teacher in elementary school. Master in Education in the Technical and Vocational Education of National Pingtung University of Science and Technology in 2014.

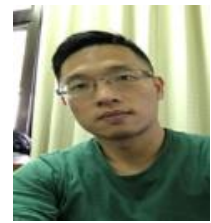

Chunyi Lee is an English lecturer from Language Center, National Pintung University of Science and Technology. He got the MA in translation studies, Newcastle University, UK.

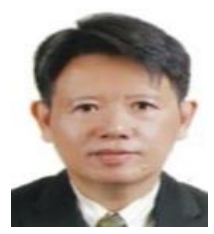

Tsai-Feng Cheng is a full professor in the Department of Education, National Kaohsiung Normal University, Taiwan. His specialties include educational administration, educational evaluation, educational leadership and organizational behavior.

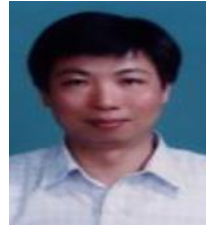

Shi-Jer Lou is a full professor in the Graduate Institute of Vocational and Technological Education, National Pingtung University of Science and Technology, Taiwan. His research interests cover areas in vocational education, teacher education, educational technology, and digital learning. 